\title{
Zonisamide for the Treatment of Parkinson Disease: A Current Update
}

\author{
Chengqian Li' ${ }^{1}$, Li Xue ${ }^{2}$, Yumei Liu' ${ }^{1}$, Zhengjie Yang ${ }^{1}$, Song Chi' and Anmu Xie ${ }^{1 *}$ \\ ${ }^{1}$ Department of Neurology, Affiliated Hospital of Qingdao University, Qingdao, China, ${ }^{2}$ Department of Medical Record, \\ Affiliated Hospital of Qingdao University, Qingdao, China
}

Zonisamide has been used as an add-on treatment in order to overcome the deficiencies of the general therapies currently used to resolve the motor complications and nonmotor symptoms of Parkinson disease. Various trials have been designed to investigate the mechanism of action and treatment effects of zonisamide in this condition. Most clinical trials of zonisamide in Parkinson disease were from Japan. The vast majority of studies used changes in the Unified Parkinson's Disease Rating Scale (UPDRS) scores and daily "OFF" time as primary endpoints. Based on adequate randomized controlled trials, zonisamide is considered a safe and efficacious add-on treatment in Parkinson disease. The most convincing proof is available for a dosage of $25-50 \mathrm{mg}$, which was shown to lead to a significant reduction in the UPDRS III score and daily "OFF" time, without increasing disabling dyskinesia. Furthermore, zonisamide may play a beneficial role in improving non-motor symptoms in PD, including impulsive-compulsive disorder, rapid eye movement sleep behavior disorder, and dementia. Among the various mechanisms reported, inhibition of monoamine oxidase-B, blocking of T-type calcium channels, modulation of the levodopa-dopamine metabolism, modulation of receptor expression, and neuroprotection are the most often cited. The mechanisms underlying neuroprotection, including modulation of dopamine turnover, induction of neurotrophic factor expression, inhibition of oxidative stress and apoptosis, inhibition of neuroinflammation, modulation of synaptic transmission, and modulation of gene expression, have been most extensively studied. This review focuses on structure, pharmacokinetics, mechanisms, therapeutic effectiveness, and safety and tolerability of zonisamide in patients with Parkinson disease.

Keywords: Parkinson's disease, zonisamide, mechanism, neuroprotection, motor fluctuations, non-motor symptoms, antiparkinsonian drug, pharmacokinetics

\section{INTRODUCTION}

After Alzheimer disease, Parkinson disease (PD) is the most prevalent neurodegenerative disorder (de Lau and Breteler, 2006; Yang and Perry, 2009). The primary pathological manifestation of $\mathrm{PD}$ is the reduction of dopamine-producing cells in the nigrostriatal pathway, which causes a significant reduction in the dopamine levels of the striatal cells (Greenamyre and Hastings, 2004; Liu et al., 2020). However, the etiology of and the mechanisms underlying the decrease in dopaminergic neurons remain unclear. At the moment, dopamine replacement drugs, such as dopamine agonists and levodopa, are generally efficacious in PD patients (Chen and Swope, 2007). Nevertheless, the effectiveness of levodopa and dopamine agonists is gradually lost, and disabling motor complications worsen as time passes, as the current drugs do not slow or halt the progression of neurodegeneration (Bonuccelli and Del Dotto, 2006; Lew, 2007). Non-motor symptoms also 
appear and threaten patients' quality of life as the disease progresses (Schapira, 2007). Therefore, there remains a need for new therapeutic strategies (Miwa, 2007). Zonisamide (ZNS) may be an effective therapeutic agent, with varied mechanisms of action relevant to the treatment of PD.

ZNS is a sulfonamide developed in Japan (Uno et al., 1979; Murata, 2004; Bermejo and Anciones, 2009). It has been approved for the treatment of seizures in Japan since 1989 and is commercially available worldwide (Miwa, 2007). Thereafter, ZNS has been authorized as an add-on treatment, along with levodopa, for PD patients in Japan since 2009 (Yang and Perry, 2009). In 2000, Murata et al. (2001) serendipitously discovered that ZNS was efficacious for both epileptic seizures and Parkinsonian symptoms in a single patient. Since then, dozens of preclinical and clinical studies have been performed to clarify the mechanisms and therapeutic effectiveness of ZNS, and the related research has progressed rapidly over the last 10 years. Since the last review was published in 2013 (Grover et al., 2013), there has been a need to summarize the studies reported in the interim. This review focuses on the structure, pharmacokinetics, mechanisms, therapeutic effectiveness, and safety and tolerability of ZNS in patients with PD.

\section{STRUCTURE}

ZNS is a sulfonamide drug (Uno et al., 1979). Its chemical name is 1,2-benzisoxazole-3-methanesulfonamide, and molecular weight is $212.227 \mathrm{~g} / \mathrm{mol}$. The chemical structure of ZNS is shown in Figure 1 .

\section{PHARMACOKINETICS}

The pharmacokinetics of ZNS has been well investigated and summarized previously (Sills and Brodie, 2007; Yang and Perry, 2009) and are shown in Table 1, based on preclinical or clinical trials, prescribing information, and previous reviews (Ito et al., 1982; Matsumoto et al., 1983; Miwa, 2007; Bermejo and Anciones, 2009).

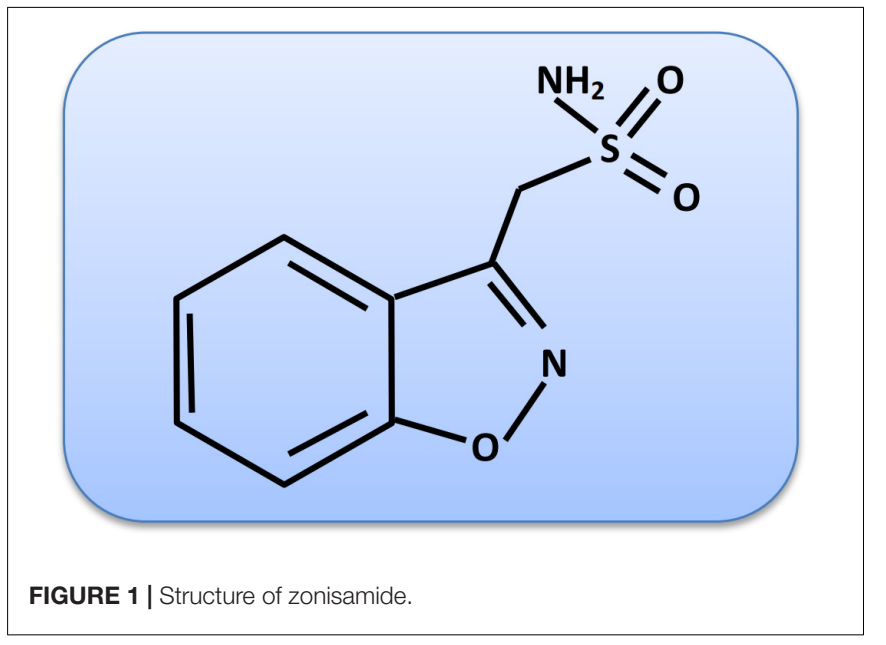

TABLE 1 | Properties of zonisamide.

\begin{tabular}{|c|c|}
\hline \multicolumn{2}{|c|}{ Zonisamide } \\
\hline Alternative names & AD-810, Zonegran ${ }^{R}$ \\
\hline ATC code & $\begin{array}{l}\text { N03A (antiepileptic drugs), N04 } \\
\text { (antiparkinsonian drugs) }\end{array}$ \\
\hline Mechanisms & See Figure 2 \\
\hline \multicolumn{2}{|l|}{ Prescription } \\
\hline Route & Orally \\
\hline Recommended dosage & $25,50 \mathrm{mg}$ \\
\hline Administration mode & Once daily \\
\hline \multicolumn{2}{|l|}{ Indication } \\
\hline \multicolumn{2}{|c|}{ Recommended as add-on treatment in patients with Parkinson disease } \\
\hline \multicolumn{2}{|c|}{$\begin{array}{l}\text { Pharmacokinetics (Uno et al., 1979; Ito et al., 1982; Matsumoto et al., 1983; } \\
\text { Stiff et al., 1992; Nakasa et al., 1998; Ohmori et al., 1998; Sills and Brodie, 2007; } \\
\text { Yang and Perry, 2009) }\end{array}$} \\
\hline $\begin{array}{l}\text { Mean maximum } \\
\text { plasma concentration (Cmax) }\end{array}$ & $2.3-12 \mathrm{mg} / \mathrm{ml}$ \\
\hline Median time (tmax) & $2.4-3.6 \mathrm{~h}$ \\
\hline Absolute bioavailability & Nearly $100 \%$ \\
\hline Apparent volume of distribution & $1.1-1.7 \mathrm{~L} / \mathrm{kg}$ \\
\hline Clearance & $1.91 \mathrm{~L} / \mathrm{h}$ \\
\hline Elimination half-life & $49.7-62.5 \mathrm{~h}$ \\
\hline Pivotal trials & See Table 2 \\
\hline Common adverse events & See Table 3 \\
\hline
\end{tabular}

ATC, Anatomical Therapeutic Chemical.

It has been demonstrated that the P450 enzyme CYP3A4 is primarily responsible for the metabolism of $\mathrm{ZNS}$, whereas CYP3A5 and CYP2C19 may also be involved (Nakasa et al., 1998; Ohmori et al., 1998; Morita et al., 2005). All ZNS derivatives, including 2-sulfamoylacetylphenol, N-acetyl ZNS, and unaltered ZNS, are excreted in the urine and feces (Stiff et al., 1992). Notably, potential interactions between ZNS and other medications for PD also need to be taken into account (Sills and Brodie, 2007; Bermejo and Anciones, 2009).

\section{MECHANISMS OF ACTION}

The antiparkinsonian mechanism of ZNS is complicated. As the treatment dosage of ZNS in PD is $25-50 \mathrm{mg} /$ day, which is markedly lower than that for the treatment of epilepsy (200-400 $\mathrm{mg} / \mathrm{day})$, the mechanism involved is likely to be different (Murata et al., 2007). Here, we will review possible mechanisms, with a particular focus on advances in the last several years, involving both dopaminergic and nondopaminergic mechanisms.

\section{Inhibition of Monoamine Oxidase-B}

ZNS is capable of inhibiting monoamine oxidase-B (MAOB) (Uemura et al., 2017). Sonsalla et al. (2010) reported that ZNS regulates MAO-B activity, reversibly, with an $\mathrm{IC}_{50}$ of $25 \mu \mathrm{M}$ in vitro.

Previous studies have demonstrated that the metabolism of dopamine by $\mathrm{MAO}-\mathrm{B}$ produces reactive oxygen species (ROS), which contribute to nigrostriatal degeneration 


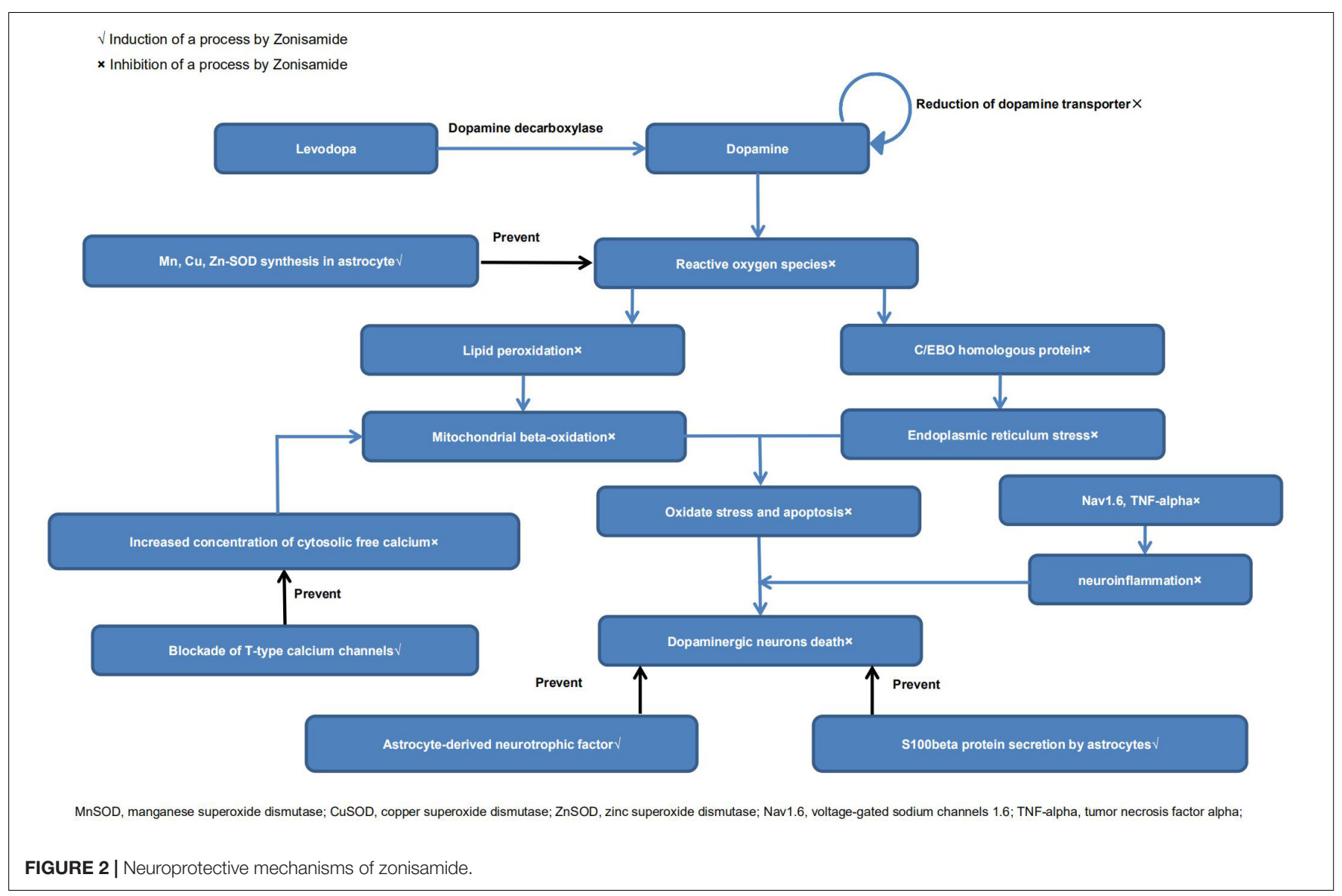

(Alborghetti and Nicoletti, 2019). ZNS prevents the formation of 1-methyl-4-phenylpyridinium $[\mathrm{MPP}(+)]$, which is derived from 1-methyl-4-phenyl-1,2,3,6-tetrahydropyridine (MPTP) via MAO-B, and thereby inhibits the oxidation of dopamine to hydrogen peroxide and the related neurotoxic effects (Siebert et al., 2000; Sonsalla et al., 2010).

\section{Blocking of T-Type Calcium Channels}

Previous experimental studies have suggested that patterns of neural firing activity in the basal nuclei in MPTP-induced mice or PD patients are switched to a bursting discharge pattern (Wang et al., 2006; Wichmann and DeLong, 2006; Bermejo and Anciones, 2009). This activity could be reduced by ZNS as this drug blocks the voltage-gated $\mathrm{Na}^{+}$channels and voltagegated $\mathrm{Ca}^{2+}$ channels (T-type calcium channels), resulting in improvement in PD symptoms (Yang et al., 2014; Kunisawa et al., 2018). Additionally, Yurekli et al. (2013) demonstrated that ZNS decreased the level of cytosolic free $\mathrm{Ca}^{2+}$ in an MPP-induced neuronal cell model of PD.

\section{Modulation of Levodopa-Dopamine Metabolism}

Nishijima et al. (2018) demonstrated that the effect of ZNS is primarily due to the modulation of levodopa-dopamine metabolism in the striatum. They found that levodopa-induced dyskinesia (LID) was significantly enhanced by prescription of ZNS. On the contrary, apomorphine-induced dyskinesia was not affected by prescription of ZNS. ZNS may enhance dopamine synthesis (Miwa, 2007). ZNS increases the intracellular dopamine concentration when the drug is administered at 25 or $50 \mathrm{mg} / \mathrm{kg}$ daily for 3 weeks (Okada et al., 1995). Murata et al. (Murata, 2004) demonstrated that enhanced expression of tyrosine hydroxylase (TH) mRNA contributed to increased dopamine synthesis. They found that levels of $\mathrm{TH}$ mRNA were increased in the rat striatum when ZNS was administered at 20 or $50 \mathrm{mg} / \mathrm{kg}$ daily for 2 weeks. However, Nishijima et al. (2018) found that a single administration of ZNS did not induce dyskinesia, and TH was not involved in levodopa metabolism. Thus, the enhanced expression of TH cannot fully explain the increased levodopa effect. Further studies are required to demonstrate this mechanism.

It has also been reported that ZNS increases the extracellular dopamine concentration, suggesting that suppression of dopamine reuptake may explain the increased extracellular dopamine concentration (Nishijima et al., 2018). It has been reported that ZNS could increase the release of dopamine (Gluck et al., 2004; Miwa, 2007). However, a recent study showed that ZNS could not elevate striatal expression of vesicular monoamine transferase-2 and dopamine decarboxylase by Western blot analyses, suggesting that it may not be the main mechanism underlying the antiparkinsonian effects of ZNS (Nishijima et al., 2018). 
TABLE 2 | Clinical trials on zonisamide effectiveness in the treatment of PD.

\begin{tabular}{|c|c|c|c|c|c|c|c|c|}
\hline Type & Authors (year) & Phase & Length of trial & $\begin{array}{l}\text { Enrolled/ } \\
\text { completed } \\
(\%)\end{array}$ & $\begin{array}{l}\text { Inclusion/exclusion } \\
\text { criteria }\end{array}$ & Dosage & Endpoints & Results \\
\hline $\begin{array}{l}\text { Open-label } \\
\text { trial }\end{array}$ & Ikeda et al. (2015) & Phase 2 & 3 months & $\begin{array}{l}10 / 10 \\
(100 \%)\end{array}$ & $\begin{array}{l}\mathrm{H}-\mathrm{Y} \text { stage I or II } \\
\text { Untreated (De Novo) } \\
\text { patients }\end{array}$ & $\begin{array}{l}25 \mathrm{mg} / \text { day for } 1 \\
\text { month and } \\
50 \mathrm{mg} / \text { day for the } \\
\text { next } 2 \text { months }\end{array}$ & $\begin{array}{l}\text { UPDRS I-IV } \\
\text { Tremor-related UPDRS (items } \\
\text { 16, 20, and 21) } \\
\text { Sleep condition }\end{array}$ & $\begin{array}{l}\text { I.UPDRS III and tremor-related scores: } \\
\text { markedly decreased }(P<0.01) \\
\text { II. Sleep state: improved markedly in } 3 \\
\text { patients with RBD }\end{array}$ \\
\hline $\begin{array}{l}\text { Open-label } \\
\text { trial }\end{array}$ & $\begin{array}{l}\text { Murata et al. } \\
\text { (2001) }\end{array}$ & Phase 2 & 12 weeks & 9/9 (100\%) & Advanced-PD patients & 50-200 mg/day & $\begin{array}{l}\text { UPDRS I-IV (ON and OFF) } \\
\text { H-Y stage (ON and OFF) } \\
\text { "OFF" time }\end{array}$ & $\begin{array}{l}\text { I. UPDRS II (OFF): clearly diminished } \\
\text { (22.3-12.3, } P<0.001) \\
\text { II. H-Y stage (OFF): clearly improved } \\
\text { (3.8-2.8, } P<0.01 \text { ) } \\
\text { III. "OFF" time: significant decreased } \\
\text { (5.9-1.2 h, } P<0.001 \text { ) }\end{array}$ \\
\hline $\begin{array}{l}\text { Double-blind } \\
\text { RCT }\end{array}$ & $\begin{array}{l}\text { Murata et al. } \\
(2007)\end{array}$ & Phase 2/3b & $\begin{array}{l}\text { UP to } 16 \text { weeks, } \\
\text { including a } 2 \text { week } \\
\text { run-in period }\end{array}$ & $\begin{array}{l}347 / 279 \\
(80.4 \%)\end{array}$ & Advanced-PD patients & $\begin{array}{l}25,50,100 \mathrm{mg} / \text { day } \\
\text { or placebo }\end{array}$ & $\begin{array}{l}\text { Primary: Variation in UPDRS III } \\
\text { Others: Variation in the } \\
\text { percentage of patients } \\
\text { with } \geq 30 \% \text { reduction in } \\
\text { UPDRS III (responders) } \\
\text { Variation in "OFF" time }\end{array}$ & $\begin{array}{l}\text { I. ZNS } 25-50 \text { mg: clearly efficacious in } \\
\text { diminishing UPDRS III scores } \\
\text { II. ZNS } 50 \text { mg: percentage of responders } \\
\text { was markedly higher } \\
\text { III. ZNS } 50 \text { mg and } 100 \mathrm{mg} \text { : clearly } \\
\text { efficacious in diminishing "OFF" time }\end{array}$ \\
\hline $\begin{array}{l}\text { Double-blind } \\
\text { RCT }\end{array}$ & $\begin{array}{l}\text { Murata et al. } \\
(2015)\end{array}$ & Phase 3 & $\begin{array}{l}16 \text { weeks, including } \\
\text { a } 4 \text { week run-in } \\
\text { period }\end{array}$ & $\begin{array}{l}422 / 354 \\
(83.9 \%)\end{array}$ & $\begin{array}{l}\text { Advanced-PD patients } \\
\text { Presence of motor } \\
\text { complications (> } 2 \mathrm{~h} \\
\text { "OFF" time/day) }\end{array}$ & $\begin{array}{l}25,50 \mathrm{mg} / \text { day or } \\
\text { placebo }\end{array}$ & $\begin{array}{l}\text { Primary: Variation in daily "OFF" } \\
\text { time } \\
\text { Others: Variation in UPDRS and } \\
\text { PDQ-39 } \\
\text { Variation in the percentage of } \\
\text { patients with } \geq 20 \% \text { reduction } \\
\text { in "OFF" time (responders) }\end{array}$ & $\begin{array}{l}\text { I. ZNS } 50 \text { mg: clearly efficacious in } \\
\text { diminishing "OFF" time ( } P=0.005 \text {, } \\
\text { difference, }-0.709 \text { h/day) } \\
\text { II. ZNS } 50 \mathrm{mg} \text { : percentage of responders } \\
\text { was markedly higher ( } 40.5 \% ; P<0.001 \text { ). } \\
\text { III. ZNS } 50 \text { mg: clearly efficacious in } \\
\text { diminishing UPDRS II (off) and UPDRS III }\end{array}$ \\
\hline $\begin{array}{l}\text { Double-blind } \\
\text { RCT }\end{array}$ & $\begin{array}{l}\text { Murata et al. } \\
(2016) \\
\text { Registration } \\
\text { number: } \\
\text { JapicCTI-101198 }\end{array}$ & Phase 3 & $\begin{array}{l}14 \text { weeks, including } \\
\text { a } 2 \text { week run-in } \\
\text { period }\end{array}$ & $\begin{array}{l}196 / 166 \\
(84.7 \%)\end{array}$ & $\begin{array}{l}\text { Advanced-PD patients } \\
\text { Deterioration of } \\
\text { response to levodopa }\end{array}$ & $\begin{array}{l}25,50 \mathrm{mg} / \text { day or } \\
\text { placebo }\end{array}$ & $\begin{array}{l}\text { Primary: Variation in UPDRS III } \\
\text { scores } \\
\text { Others: Variation in the } \\
\text { percentage of patients } \\
\text { with } \geq 30 \% \text { reduction in } \\
\text { UPDRS III (responders) } \\
\text { Variation in UPDRS II scores }\end{array}$ & $\begin{array}{l}\text { I. ZNS } 25 \text { mg: clearly efficacious in } \\
\text { diminishing UPDRS III scores. }(P=0.029) \\
\text { II. ZNS } 50 \text { mg: percentage of responders } \\
\text { was markedly higher ( } P=0.038 \text { ) } \\
\text { III. ZNS } 25 \text { mg: clearly efficacious in } \\
\text { diminishing UPDRS II (off) score } \\
(P=0.039)\end{array}$ \\
\hline
\end{tabular}

ZNS, zonisamide; RCT, randomized controlled trials; H-Y stage, Hoehn and Yahr stage; UPDRS, Unified Parkinson's Disease Rating Scale; PDQ-39, Parkinson's Disease Questionnaire-39; RBD, rapid eye movement sleep behavior disorder. 
TABLE 3 | Side effects related to ZNS therapy that appear in more than $3 \%$ of participants.

\begin{tabular}{|c|c|c|c|c|c|c|c|c|c|c|c|c|}
\hline \multirow[t]{2}{*}{ Side effects } & \multicolumn{4}{|c|}{$\begin{array}{c}\text { Phase } 3 \text { trials } \\
\text { (Murata et al., 2015) }\end{array}$} & \multicolumn{3}{|c|}{$\begin{array}{c}\text { Phase } 3 \text { trials } \\
\text { (Murata et al., 2016) }\end{array}$} & \multicolumn{5}{|c|}{$\begin{array}{c}\text { Phase } 2 \mathrm{~b} / 3 \text { trials } \\
\text { (Murata et al., 2007) }\end{array}$} \\
\hline & PLC & $\begin{array}{c}\text { ZNS } \\
25 \mathrm{mg}\end{array}$ & $\begin{array}{l}\text { ZNS } \\
50 \mathrm{mg}\end{array}$ & Total & PLC & $\begin{array}{c}\text { ZNS } \\
25 \mathrm{mg}\end{array}$ & $\begin{array}{l}\text { ZNS } \\
50 \mathrm{mg}\end{array}$ & PLC & $\begin{array}{l}\text { ZNS } \\
25 \mathrm{mg}\end{array}$ & $\begin{array}{l}\text { ZNS } \\
50 \mathrm{mg}\end{array}$ & $\begin{array}{c}\text { ZNS } \\
100 \mathrm{mg}\end{array}$ & Total \\
\hline Total & $49.6 \%$ & $57.7 \%$ & $60.9 \%$ & $59.3 \%$ & $65.1 \%$ & $55.6 \%$ & $60.3 \%$ & $65.1 \%$ & $70.9 \%$ & $72.9 \%$ & $79.5 \%$ & / \\
\hline Constipation & $1.5 \%$ & $1.5 \%$ & $3.1 \%$ & $2.3 \%$ & $6.3 \%$ & $1.6 \%$ & $1.6 \%$ & $3.6 \%$ & $6.3 \%$ & $8.2 \%$ & $4.8 \%$ & $6.5 \%$ \\
\hline Nasopharyngitis & $6.9 \%$ & $7.7 \%$ & $3.9 \%$ & $5.8 \%$ & $11.1 \%$ & $4.8 \%$ & $3.2 \%$ & / & / & / & / & / \\
\hline Bronchitis & $2.3 \%$ & $1.5 \%$ & $3.1 \%$ & $2.3 \%$ & / & / & / & l & / & / & / & / \\
\hline Contusion & $3.1 \%$ & $2.3 \%$ & $1.6 \%$ & $1.9 \%$ & / & / & / & / & / & / & / & / \\
\hline Blood LDH increased & $3.1 \%$ & $2.3 \%$ & $3.1 \%$ & $2.7 \%$ & / & / & / & / & / & / & / & / \\
\hline Blood urea increased & $1.5 \%$ & $3.1 \%$ & $0.8 \%$ & $1.9 \%$ & / & / & / & / & / & / & / & / \\
\hline Decreased appetite & $3.1 \%$ & $4.6 \%$ & $0.8 \%$ & $2.7 \%$ & $6.3 \%$ & $4.8 \%$ & $1.6 \%$ & $14.5 \%$ & $5.1 \%$ & $8.2 \%$ & $16.9 \%$ & $10.1 \%$ \\
\hline Dyskinesia & $7.6 \%$ & $6.9 \%$ & $7.0 \%$ & $7.0 \%$ & $1.6 \%$ & $8.2 \%$ & $3.2 \%$ & l & l & l & / & / \\
\hline Somnolence & $2.3 \%$ & $3.1 \%$ & $6.3 \%$ & $4.7 \%$ & / & / & l & $4.8 \%$ & $1.3 \%$ & $15.3 \%$ & $15.7 \%$ & $10.9 \%$ \\
\hline Insomnia & $3.1 \%$ & $3.1 \%$ & $0.0 \%$ & $1.6 \%$ & $7.9 \%$ & $4.8 \%$ & $4.8 \%$ & / & / & / & / & / \\
\hline Apathy & / & / & / & / & / & / & / & $6.0 \%$ & $7.6 \%$ & $7.1 \%$ & $10.8 \%$ & $8.5 \%$ \\
\hline Dizziness & / & / & / & / & / & / & / & $7.2 \%$ & $3.8 \%$ & $5.9 \%$ & $7.2 \%$ & $5.7 \%$ \\
\hline Weight loss & / & / & / & / & $6.3 \%$ & $0 \%$ & $4.8 \%$ & $4.8 \%$ & $7.6 \%$ & $3.5 \%$ & $9.6 \%$ & $6.9 \%$ \\
\hline Increased in serum CK & / & / & / & / & $6.3 \%$ & $4.8 \%$ & $1.6 \%$ & $8.4 \%$ & $8.9 \%$ & $8.2 \%$ & $4.8 \%$ & $7.3 \%$ \\
\hline
\end{tabular}

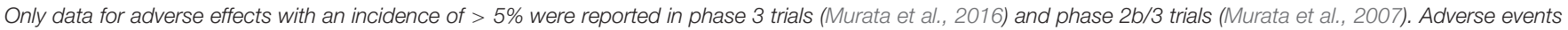
affecting $>5 \%$ are in bold font. ZNS, zonisamide; PLC, placebo; LDH, lactate dehydrogenase; CK, creatinine phosphokinase; /, not reported.

\section{Modulation of Receptor Expression}

Recently, Oki et al. (2017) reported that ZNS could ameliorate LID by modulating the expression of receptors. They designed different models of levodopa-ZNS administration in four groups, namely, intermittent ZNS and levodopa injection, intermittent levodopa injection, continuous levodopa infusion, and no medication. Two weeks after the treatment, they analyzed the mRNA expression of endocannabinoid $\mathrm{CB} 1$ receptor, $\mathrm{D}_{1}$ and $\mathrm{D}_{2}$ receptors, and adenosine $\mathrm{A} 2 \mathrm{~A}$ receptor in the striatum of $\mathrm{PD}$ model rats in each group. Their results indicated that intermittent prescription of levodopa induced LID, which was related to the upregulation of dopamine $\mathrm{D}_{1}$ and adenosine $\mathrm{A} 2 \mathrm{~A}$ receptors. ZNS injection improved LID by downregulation of adenosine A2A and endocannabinoid $\mathrm{CB} 1$ receptors.

\section{Neuroprotection}

It has been reported that ZNS could inhibit the reduction of dopamine-producing cells in neurotoxin-induced animal models of PD (Willmore, 2005; Rosler et al., 2010; Sonsalla et al., 2010; Ikeda et al., 2018). There are indeed a growing number of studies that have explored its neuroprotective effects (Bermejo and Anciones, 2009; Santos, 2012). Below, we review the possible mechanisms. A diagrammatic illustration of the neuroprotective mechanisms of ZNS is shown in Figure 2.

\section{Modulation of Dopamine Turnover}

Choudhury et al. $(2011,2012)$ reported that ZNS protected dopamine-producing cells in MPTP-treated models of PD, which may be related to increased S100beta secretion by astrocytes. ZNS also increased dopamine turnover, as surviving dopaminergic neurons recovered the production of dopamine after ZNS prescription (Choudhury et al., 2011). Yokoyama et al. (2010) reported that treatment with ZNS significantly prevented the dopaminergic neuronal damage and proliferation of microglia and increased TH protein levels. Furthermore, they found that ZNS significantly attenuated the motor syndrome a week after MPTP treatment in the behavioral study. Additionally, Ikeda et al. (2018) demonstrated that ZNS treatment delayed the reduction of striatal presynaptic dopamine transporter levels, suggesting that ZNS may play an essential role in slowing the deterioration of early stage PD. They examined the average specific binding ratio (SBR) of dopamine by dopamine transporter single-photon emission computed tomography at the baseline. The SBR decline rate was significantly reduced in the ZNS group, whereas the SBR was significantly reduced in the placebo at the endpoint.

Notably, Yano et al. (2009) mentioned that ZNS could prevent MPTP-induced increases in the levels of glial fibrillary acidic protein in striatal neurons, but Choudhury et al. (2011) came to the opposite conclusion. Further studies are needed to resolve this contradiction.

\section{Induction of Neurotrophic Factors}

Sano et al. (2015) reported that ZNS could reduce the death of nigrostriatal dopamine-producing neurons via signal transduction by neurotrophic factors. There were increased levels of brain-derived neurotrophic factors in the substantia nigra and striatum in the ZNS group compared with placebo. Choudhury et al. (2012) found that ZNS increased the expression of neurotrophic factors in astrocytes.

An experimental study has reported that ZNS could enhance neurite elongation after nerve injury in primary motor neurons in vitro (Yagi et al., 2015). They also found that ZNS could enhance neurite regeneration and protect primary 
motor neurons against oxidative stress by inducing increased expression of neurotrophic factors (neurotrophin-4/5, brainderived neurotrophic factors, and nerve growth factors) and their receptors. Further studies are needed to demonstrate whether ZNS has similar effects in nigrostriatal dopaminergic cells.

\section{Inhibition of Oxidative Stress and Apoptosis}

Some findings have suggested that ZNS exerts neuroprotective effects mainly via antioxidant action. Ueno et al. (2018) reported that long-chain acylcarnitine (LCAC) levels were raised in $\mathrm{PD}$ patients after ZNS treatment. As an increase in LCACs implies improvement in mitochondrial beta-oxidation, ZNS may have antioxidant properties. Condello et al. (2013) reported that ZNS could reduce intracellular ROS levels and restore mitochondrial membrane potential. Costa et al. (2010) found that ZNS could protect the striatum against irreversible mitochondrial impairment through a $\gamma$-aminobutyric acid (GABA)-mediated mechanism. Choudhury et al. (2012) and Kawajiri et al. (2010) reported that ZNS could increase levels of manganese/copper/zinc superoxide dismutase $(\mathrm{Mn} / \mathrm{Cu} / \mathrm{Zn}$ SOD) in astrocytes. Yurekli et al. (2013) demonstrated that ZNS could induce modulating effects that increased glutathione (GSH) and glutathione peroxidase levels. Concentrations of cytosolic free $\mathrm{Ca}^{2+}$ and lipid peroxidation were also lower in ZNS treatment groups (Yurekli et al., 2013; Ueno et al., 2018). Asanuma et al. $(2008,2010)$ found that ZNS prevented levodopa-induced dopamine quinone formation in the striatum. They also found that ZNS treatment significantly increased GSH levels by enhancing the expression of cystine/glutamate exchange transporter (xCT). However, Bentea et al. (2017) reached the opposite conclusion. In their experiments, ZNS did not alter GSH levels or influence the expression of $\mathrm{xCT}$ both in vivo and in vitro. More experiments are needed to resolve the contradiction. Moreover, ZNS exerted antiapoptotic effects, as demonstrated by increased cell viability and attenuated caspase- 3 activity in human neuroblastoma (SH-SY5Y) cells (Kawajiri et al., 2010; Condello et al., 2013).Tsujii et al. (2015a,b) reported that ZNS had neuroprotective effects against endoplasmic reticulum (ER) stress. ZNS inhibited SH-SY5Y cell death in vitro and suppressed ER stress-related cell death in vivo via inhibiting the expression of ER stress-induced factors. Furthermore, ZNS suppressed ER stress-related neuron death by inhibiting caspase3 activation (Yurekli et al., 2013; Tsujii et al., 2015b). Omura et al. (2012, 2013) reported that ZNS inhibited caspase-3 activation via increases in HMG-CoA reductase degradation 1 protein levels. These studies demonstrated that inhibition of ER stress, especially the mechanism via caspase-3, was involved in the neuroprotective actions of ZNS.

\section{Inhibition of Neuroinflammation}

Hossain et al. (2018) reported that ZNS may potentially modify the disease by inhibition of microglial voltage-gated sodium channels 1.6 (Nav1.6), as well as neuroinflammation. Nav1.6 is expressed in microglial cells of MPTP-induced PD mice and postmortem PD brains, and it contributes to neuroinflammation. ZNS also inhibited the MPTP-induced expression of tumor necrosis factor $\alpha$ and gp91 (phox). Together, these findings suggest that ZNS can reduce neuroinflammation and has neuroprotective potential.

\section{Modulation of Synaptic Transmission}

It is also possible that ZNS has an effect on synaptic transmission. Experimental studies have suggested that ZNS affects synaptic transmission related to the kynurenine pathway in astroglia (Fukuyama et al., 2014). ZNS could increase the release of metabotropic glutamate-receptor (mGluR) agonists from astrocytes, and activated mGluR agonists inhibited neurotransmission in both direct and indirect pathways, which may explain the efficacy and tolerability of ZNS in PD (Fazio et al., 2012; Copeland et al., 2013; Fukuyama et al., 2014). Yamamura et al. (2009) found that ZNS could influence the level of extracellular neurotransmitters in a dose-dependent manner. Striatal perfusion of ZNS increased the extracellular levels of dopamine in striatal cells and attenuated extracellular levels of GABA in both the subthalamic nucleus and globus pallidus. Extracellular levels of glutamate in the substantia nigra pars reticulata $(\mathrm{SNr})$ were also decreased. Furthermore, they demonstrated that ZNS inhibited the indirect pathways of movement. Sano and Nambu (2019) examined neuronal activities in the $\mathrm{SNr}$ and found that ZNS administration showed longer inhibition and reduced late excitation, which suggested that ZNS may enhance the direct pathway, while inhibiting the indirect pathway (Tachibana et al., 2008; Sano et al., 2013).

\section{Modulation of Gene Expression}

Arawaka et al. (2014) demonstrated that ZNS had neuroprotective effects in a genetic model of PD by attenuating A53T $\alpha$-synuclein-induced neurotoxicity. They found that ZNS could prevent the loss of dopamine-producing cells by inhibiting a cell death pathway or cellular damage caused by $\alpha$-synuclein. Furthermore, Ueda et al. (2012) found that ZNS upregulated the expression of several genes associated with nervous system function and development, such as Gpr143 and Bdnf, and of some genes associated with metabolism, including Aldh1a7, Akr1b7, Dhdh, and Agmat. Moreover, ZNS downregulated the expression of a few genes associated with inflammation and the immune system.

Recently, Cha et al. (2020) identified a ZNS-responsive gene in PD patients. Carriers of mouse double-minute 4 (MDM4) gene had higher ZNS sensitivity, improved motor fluctuation, and reduced "OFF" time. Inhibition of p53 is associated with upregulation of MDM4. The association between higher MDM4 expression and "OFF" time reduction suggested that p53 downregulation may prevent the reduction of dopamineproducing cells and deterioration of PD.

\section{Other Possible Mechanisms}

Recently, some studies have investigated cell replacement therapy using induced pluripotent stem cells (iPSCs) for the treatment of PD (Freed et al., 2001; Olanow et al., 2003; Mendez et al., 2005; Hargus et al., 2010; Rhee et al., 2011). Yoshikawa et al. (2013) reported that ZNS administration improved the survival and differentiation of iPSC-derived dopaminergic neuronal in murine brains. ZNS improved the efficacy of cell replacement 
therapy for treating PD. Indeed, cell replacement therapy using iPSCs might be a novel therapy strategy for PD in the future.

\section{CLINICAL EFFECTIVENESS OF ZONISAMIDE}

Murata et al. (2001) incidentally found that ZNS was effective in treating PD patients. Since then, several clinical trials have been performed to explore the effectiveness of ZNS for the treatment of PD. Based on adequate randomized controlled trials (RCTs), ZNS is efficacious and safe as an adjunctive therapy in patients with $\mathrm{PD}$ (Janszky, 2009; Matsunaga et al., 2017). Additionally, the 2018 guideline has supported the use of ZNS for motor symptoms, especially for treating motor fluctuations (Fox et al., 2018). We review the clinical trials below; further details are summarized in Table 2.

\section{De novo/Early Stage PD}

A preliminary, open-label (OL) trial (Ikeda et al., 2015) conducted in Japan suggested that a single administration of ZNS was efficacious in improving motor and sleep dysfunction in treatment-naive patients with early stage PD. Moreover, ZNS was recommended as adjunctive therapy in early stage/stable PD according to 2018 guidelines (Fox et al., 2018).

\section{Advanced-Stage PD}

The largest area of the potential use of ZNS is as adjunctive therapy for motor fluctuations (Fox, 2013). ZNS improved the motor functions and wearing-off phenomenon without worsening dyskinesia in advanced-PD patients (Murata, 2009; Fox et al., 2018). Four clinical trials by published in 2001, 2007, 2015, and 2016 Murata et al. (2001, 2007, 2015, 2016), have examined the efficacy of ZNS in 974 advanced-PD patients.

\section{Phase 2 Trials}

An OL trial on nine patients with advanced PD showed that ZNS has beneficial effects in improving the primary symptoms of PD, including motor fluctuations (Murata et al., 2001). The Unified Parkinson's Disease Rating Scale (UPDRS) score, Hoehn and Yahr stage (H-Y stage), and "OFF" time per day were assessed after 12 weeks of ZNS treatment. Both the UPDRS score and H-Y stage (ON/OFF) improved, and unexpectedly, the duration of the "OFF" time markedly improved. These effects continued for more than a year, even for advanced-PD patients. Additionally, ZNS has a long half-life ( $25 \mathrm{mg}: 90 \mathrm{~h}$ ), and its beneficial effects could be maintained throughout a day with a single dose of the drug per day (Murata et al., 2015).

\section{Phase $2 b / 3$ Trials}

Murata et al. (2007) conducted an RCT in Japan to assess the efficacy of a daily dose of 25,50 , and $100 \mathrm{mg}$ of ZNS in 347 advanced-PD patients. ZNS 25 and $50 \mathrm{mg}$ resulted in significant decreases in UPDRS III total scores from baseline (ZNS $25 \mathrm{mg},-6.3 \pm 0.8$; ZNS $50 \mathrm{mg},-5.8 \pm 0.8$, as compared with $-2.0 \pm 0.8$ in placebo; $P=0.001$ and $P=0.003$, respectively; Dunnett test). Likewise, the percentage of responders, defined as patients with a reduction of $\geq 30 \%$ in UPDRS part III scores, was significantly higher with ZNS $50 \mathrm{mg}(38.8 \%, P=0.018)$ than with placebo (22.0\%). ZNS $50 \mathrm{mg}$ and ZNS $100 \mathrm{mg}$ groups achieved significant improvements in reducing the total "OFF" time [the mean changes were $-1.30 \mathrm{~h}(P=0.014)$ and $-1.63 \mathrm{~h}(P=0.013)$, respectively] compared with the placebo group. Importantly, ON time with annoying dyskinesia did not increase in any ZNS group as compared with placebo; in contrast, a reduction in disabling dyskinesia was observed in the ZNS 50 mg group.

\section{Phase 3 Trials}

Two phase 3 multicenter RCTs (Murata et al., 2015, 2016) have investigated the efficacy of ZNS among 618 advanced-PD patients: the Murata et al. (2015) and Murata et al. (2016) studies.

The Murata, 2015 study (Murata et al., 2015) examined the effectiveness of ZNS in the reduction of "OFF" time in advanced$\mathrm{PD}$ patients with motor fluctuation as compared with placebo. The primary endpoint was the variation in daily "OFF" time from baseline to the end of a 12-week prescription, according to diarized information at the final assessment. ZNS $50 \mathrm{mg}$ met the primary endpoint and had the most significant efficacy, having a significantly longer decrease in daily "OFF" time at week 12 than placebo (ZNS $50 \mathrm{mg}$ daily "OFF" time decrease: $-0.719 \pm 0.179 \mathrm{~h}$, compared with placebo: $-0.011 \pm 0.173 \mathrm{~h}$; $P=0.005)$. Moreover, the percentage of participants with a reduction in "OFF" time $\geq 20 \%$ (responders) from the beginning of treatment to week 16 was markedly higher in those receiving ZNS $50 \mathrm{mg}$ than those receiving placebo $(40.5 \%$ for ZNS $50 \mathrm{mg}$ vs. $20.9 \%$ for placebo; $P<0.001$ ). ZNS $50 \mathrm{mg}$ also resulted in statistically significant improvements in the UPDRS II (OFF) score $(P=0.021)$ and UPDRS III score at week 12 vs. placebo. However, UPDRS I, UPDRS II (ON), UPDRS IV, and Parkinson's Disease Questionnaire39 scores did not show statistically significant differences in improvements between ZNS $50 \mathrm{mg}$ and placebo. Moreover, the increase in the dyskinesia duration at week 12 was not statistically significant in those receiving ZNS $25 \mathrm{mg}$ and $50 \mathrm{mg}$ as compared with placebo $(P=0.103$ and $P=0.235$, respectively). This study demonstrated that ZNS $50 \mathrm{mg}$ could significantly reduce the "OFF" time and improve the "OFF" status of activity in advanced-PD patients who exhibited the "wearing-off phenomenon."

The Murata, 2016 study (Murata et al., 2016) explored the effectiveness and safety of ZNS 25 and $50 \mathrm{mg}$ taken orally once daily, as compared with placebo. The primary endpoint was the variation from the beginning of the treatment to the final assessment in UPDRS part III scores. ZNS $25 \mathrm{mg}$ met the primary endpoint at the final assessment, showing a marked reduction in UPDRS III scores than placebo at week $14(-5.09 \pm 0.9$ for ZNS $25 \mathrm{mg}$ vs. $-2.9 \pm 0.9$ for placebo, $P=0.029$ ). Likewise, ZNS $50 \mathrm{mg}$ resulted in a significant reduction in UPDRS III total scores at week $12(-6.1 \pm 1.0, P=0.049)$. The percentage of participants with a reduction in UPDRS III scores $\geq 30 \%$ from baseline to week 14 (responders) was markedly higher with ZNS $50 \mathrm{mg}$ than with placebo ( $45.8 \%$ for ZNS $50 \mathrm{mg}$ vs. $27.0 \%$ for placebo; $P<0.038$ ). Furthermore, the UPDRS II (OFF) scores 
were significantly improved with ZNS $25 \mathrm{mg}$ than with placebo $(P=0.039)$.

\section{Late-Stage PD}

Patients with late-stage PD (LSPD) refer to those whose H-Y stage $\geq 4$ while in the "ON" time (Fabbri et al., 2018). In a phase 2 OL study (Murata et al., 2001) by Murata, 4 of 10 patients fulfilled the LSPD definition. Two patients reached significant improvements in the UPDRS and $\mathrm{H}-\mathrm{Y}$ stage, whereas the other two did not. In another two phase 3 RCTs (Murata et al., 2007, 2015), further analyses of $\mathrm{H}-\mathrm{Y}$ stage $4-5$ patients were not available.

For safety data of the clinical studies above, see Safety and Tolerability.

\section{Effect on PD-Related Tremors}

ZNS may have an effect on intractable tremor (Bermejo and Anciones, 2009; Mochio et al., 2012; Kaplan and Tarsy, 2013). A preliminary OL trial (Nakanishi et al., 2003) performed by Nakanishi et al. reported a potentially valuable role of ZNS in PD patients with residual resting tremor. Seven of nine patients $(P<0.0017)$ had a decrease in the scale of tremor with ZNS administration. Iijima et al. (2011) also reported a case where ZNS was efficacious against re-emergent and residual resting tremor in PD. Both re-emergent and intractable resting tremors markedly decreased with a dosage of $100 \mathrm{mg} /$ day. ZNS was welltolerated, although mild sleepiness was observed. As previously suggested, ZNS had a beneficial effect on essential tremor (ET) (Ondo, 2006, 2007; Zesiewicz et al., 2007; Bermejo et al., 2008). Another study conducted by Bermejo et al. suggested that ZNS was beneficial to patients with comorbid ET and PD (Bermejo, 2007). In fact, ZNS is effective in controlling symptoms of both disorders. ZNS could thus be a good therapeutic option as adjunctive therapy in PD-related tremor (Freitas and Fox, 2016).

\section{Effects on Non-motor Symptoms Impulsive-Compulsive Disorders}

Impulse control behaviors (ICBs) belong to impulsivecompulsive disorders, which are associated with dopamine replacement therapy in PD (Evans et al., 2006; Raja and Bentivoglio, 2012). Recently, Kon et al. (2018) found that patients who developed ICB at final evaluation were prescribed ZNS earlier and at a higher dosage than other patients, suggesting that ZNS may be associated with ICB. In another study, ZNS increased novelty-seeking behaviors in mice, which were risk factors for ICB (Voon et al., 2011; Uemura et al., 2017). Thus, ZNS might be related to the development of impulsivecompulsive disorders (ICDs) in PD. However, an OL trial (Bermejo et al., 2010) performed by Bermejo et al. suggested that ZNS could play an essential positive role in ICDs. The severity of ICBs was significantly reduced, from -5.8 to -4.8 (mean change). It is important that further RCTs estimate the effectiveness of ZNS on ICDs in patients with PD.

\section{Rapid Eye Movement Sleep Behavior Disorder}

Rapid eye movement sleep behavior disorder (RBD) is considered one of the most prevailing non-motor symptoms in PD patients
(Mollenhauer et al., 2016). It may occur several years before the first symptoms of PD or during the progression of PD (Claassen et al., 2010). Recently, Kataoka and Ueno (2012) reported a case in which treatment with ZNS resolved dreamenacting behaviors and vivid nightmares in an early stage PD patient, suggesting that ZNS might be efficacious for the management of RBD. Further studies are required to estimate the effectiveness of ZNS on RBD in early- and advanced-stage PD patients.

\section{Dementia}

Dementia is described as an essential complication in PD (Iwaki et al., 2019). Iwaki et al. (2019) and Murata et al. (2007) demonstrated that ZNS may reduce the development of cognitive impairment better than other antiparkinsonian drugs. Although the vast majority of trials were performed in the Japanese population, Tombini et al. (2013) reported the case of a 78 years old Caucasian male patient with PD and dementia, who later developed epilepsy. ZNS significantly improved his seizure and extrapyramidal symptoms without affecting his cognitive status. Further RCTs are needed to evaluate the efficacy of ZNS in preventing cognitive decline among PD patients of different ethnicities (Grover et al., 2013; Tombini et al., 2013).

\section{SAFETY AND TOLERABILITY}

Generally, the therapeutic dose of ZNS for epilepsy (300-600 mg/day) is much higher than that needed for PD (Arzimanoglou and Rahbani, 2006; Ohtahara, 2006). We believe that ZNS is a safe treatment for PD as it has been applied for seizures in Japan for more than 30 years and is well-tolerated.

By now, ZNS has been prescribed to $974 \mathrm{PD}$ patients in four clinical trials by Murata et al. $(2001,2007,2015,2016)$ these studies have suggested that ZNS has high safety without a doseresponse relationship for common adverse events. Incidences of adverse events associated with ZNS treatment are summarized in Table 3.

In a phase 2 trial, the reported side effects were dry mouth $(n=1)$ and the exaggeration of dyskinesia $(n=4)$ (Murata et al., 2001). Notably, doses of ZNS in that study were as high as $50-300 \mathrm{mg} /$ day, and the exaggeration of dyskinesia could disappear with a reduction of levodopa dosage.

In a phase $2 \mathrm{~b} / 3$ trial, the most frequently reported adverse effects in the total ZNS group, as compared with placebo, were apathy $(8.5 \%)$, constipation $(6.5 \%)$, weight loss $(6.9 \%)$, and somnolence (10.9\%) (Murata et al., 2007). Although the incidences of some adverse events for ZNS $50 \mathrm{mg}$ and $100 \mathrm{mg}$ were higher than those for the placebo, there were no statistical differences in the incidences of dyskinesia and hallucination, which are both mostly observed adverse effects of antiparkinsonian drugs, between ZNS groups and placebo, indicating that ZNS is well-tolerated in PD patients at doses of $25-100 \mathrm{mg} /$ day.

In the phase 3 Murata et al. (2015) trial, ZNS $25 \mathrm{mg}$ and $50 \mathrm{mg}$ were well-tolerated in PD patients (Murata et al., 2015). The 
incidences of total adverse events reported in ZNS $25 \mathrm{mg}$ (57.7\%) and $50 \mathrm{mg}(60.9 \%)$ were not statistically different from those in placebo $(49.6 \% ; P>0.05)$. The incidence of somnolence and that of constipation for ZNS $50 \mathrm{mg}$ were higher than that for placebo (somnolence: $2.3 \%$ for placebo, $3.1 \%$ for ZNS $25 \mathrm{mg}, 6.3 \%$ for ZNS $50 \mathrm{mg}$; constipation: $1.5,1.5$, and $3.1 \%$, respectively). Hallucination and dyskinesia did not occur more frequently for ZNS $25 \mathrm{mg}$ or $50 \mathrm{mg}$ than for placebo.

In the phase 3 Murata et al. (2016) trial, ZNS $25 \mathrm{mg}$ and $50 \mathrm{mg}$ were also well-tolerated in PD patients (Murata et al., 2016). The incidences of adverse events reported in the ZNS $25 \mathrm{mg}$ (55.6\%) and $50 \mathrm{mg}(60.3 \%)$ groups were not statistically different from that in placebo $(65.1 \% ; P=0.363$ and $P=0.713$, respectively). The incidence of adverse events that occurred in more than $5 \%$ of participants was similar in all three groups. As in the Murata et al. (2015) study, dyskinesia and hallucination did not occur more frequently in ZNS 25 and $50 \mathrm{mg}$ compared with placebo. The incidences of abnormal changes in vital signs, 12-lead resting electrocardiogram, and laboratory tests were low in all groups.

Moreover, a large-scale study in Japan compared ZNS with other antiparkinsonian drugs by analyzing the associations between the administration of eight different varieties of antiparkinsonian drugs and the incidence of PD-relevant symptoms (Iwaki et al., 2019). Iwaki et al. conducted this study based on real-world data from Japan for 2008 to 2014. They demonstrated that ZNS had lower incidences of insomnia, gastric ulcers, and dementia than three of seven other anti-PD drugs $(P<0.05)$.

It is important that medical doctors should remember to ask patients about sulfa-allergies before prescribing ZNS because it is a sulfonamide (Yang and Perry, 2009).

\section{DISCUSSION}

The sulfonamide ZNS exhibits both dopaminergic and nondopaminergic mechanisms. It is a T-type calcium-channel antagonist and a reversible MAO-B inhibitor. It could modulate levodopa-dopamine metabolism and expression of various receptors. Most importantly, it has the potential for neuroprotection via various mechanisms, such as modulation

\section{REFERENCES}

Alborghetti, M., and Nicoletti, F. (2019). Different generations of Type-B monoamine oxidase inhibitors in parkinson's disease: from bench to bedside. Curr. Neuropharmacol. 17, 861-873. doi: 10.2174/ 1570159x16666180830100754

Arawaka, S., Fukushima, S., Sato, H., Sasaki, A., Koga, K., Koyama, S., et al. (2014). Zonisamide attenuates alpha-synuclein neurotoxicity by an aggregationindependent mechanism in a rat model of familial Parkinson's disease. PLoS One 9:e89076. doi: 10.1371/journal.pone.0089076

Arzimanoglou, A., and Rahbani, A. (2006). Zonisamide for the treatment of epilepsy. Expert Rev. Neurother. 6, 1283-1292. doi: 10.1586/14737175.6.9. 1283

Asanuma, M., Miyazaki, I., Diaz-Corrales, F. J., Kimoto, N., Kikkawa, Y., Takeshima, M., et al. (2010). Neuroprotective effects of zonisamide target astrocyte. Ann. Neurol. 67, 239-249. doi: 10.1002/ana.21885 of dopamine turnover, induction of neurotrophic factors, inhibition of oxidative stress and apoptosis, inhibition of neuroinflammation, modulation of synaptic transmission, and modulation of gene expression. ZNS has a dose-dependent pharmacokinetic profile and has high bioavailability. It interacts with CYP3A4.

The current studies show that ZNS is effective and safe at $25-50 \mathrm{mg} /$ day as an adjunctive therapy in patients with PD. Given the general beneficial effect and safety profile, we recommend initiating this drug at $25 \mathrm{mg} /$ day and titrating it to $50 \mathrm{mg} /$ day when needed. ZNS $50 \mathrm{mg}$ could reduce the "OFF" time, while not increasing troublesome dyskinesia in PD patients with the "wearing-off phenomenon." ZNS is well-tolerated, with few associated adverse events.

There are still a few limitations in the administration of ZNS. The vast majority of clinical trials of ZNS have been conducted in Japan, and the antiparkinsonian mechanism of ZNS remains incompletely clarified. Further RCTs are needed to estimate the effectiveness of ZNS in PD patients of different ethnicities. Moreover, further in-depth research on the antiparkinsonian mechanism of ZNS is needed.

\section{AUTHOR CONTRIBUTIONS}

CL carried out the literature retrieval, wrote the manuscript, and made the tables and figures. LX, YL, ZY, and SC critically modified the manuscript. AX funded this project, critically modified the manuscript, and supervised this work. All authors have seen and approved the final version of the manuscript.

\section{FUNDING}

This work was funded by the grants from the National Natural Science Foundation of China (No. 81971192).

\section{ACKNOWLEDGMENTS}

We would like to thank Editage (www.editage.com) for English language editing.

Asanuma, M., Miyazaki, I., Diaz-Corrales, F. J., Miyoshi, K., Ogawa, N., and Murata, M. (2008). Preventing effects of a novel anti-parkinsonian agent zonisamide on dopamine quinone formation. Neurosci. Res. 60, 106-113. doi: 10.1016/j.neures.2007.10.002

Bentea, E., Van Liefferinge, J., Verbruggen, L., Martens, K., Kobayashi, S., Deneyer, L., et al. (2017). Zonisamide attenuates lactacystin-induced parkinsonism in mice without affecting system xc. Exp. Neurol. 290, 15-28. doi: 10.1016/j. expneurol.2016.12.009

Bermejo, P. E. (2007). Zonisamide in patients with essential tremor and Parkinson's disease. Mov. Disord. 22, 2137-2138. doi: 10.1002/mds. 21717

Bermejo, P. E., and Anciones, B. (2009). A review of the use of zonisamide in Parkinson's disease. Ther. Adv. Neurol. Disord. 2, 313-317. doi: 10.1177/ 1756285609338501

Bermejo, P. E., Ruiz-Huete, C., and Anciones, B. (2010). Zonisamide in managing impulse control disorders in Parkinson's disease. J. Neurol. 257, 1682-1685. doi: $10.1007 /$ s00415-010-5603-7 
Bermejo, P. E., Ruiz-Huete, C., Dorado, R., and Anciones, B. (2008). [Zonisamide in refractory essential tremor]. Rev. Neurol. 46, 139-142.

Bonuccelli, U., and Del Dotto, P. (2006). New pharmacologic horizons in the treatment of Parkinson disease. Neurology 67(7 Suppl. 2), S30-S38. doi: 10. 1212/wnl.67.7_suppl_2.s30

Cha, P. C., Satake, W., Ando-Kanagawa, Y., Yamamoto, K., Murata, M., and Toda, T. (2020). Genome-wide association study identifies zonisamide responsive gene in Parkinson's disease patients. J. Hum. Genet. 65, 693-704. doi: 10.1038/ s10038-020-0760-8

Chen, J. J., and Swope, D. M. (2007). Pharmacotherapy for Parkinson's disease. Pharmacotherapy 27(12 Pt 2), 161S-173S. doi: 10.1592/phco.27.12part2.161S

Choudhury, M. E., Moritoyo, T., Kubo, M., Kyaw, W. T., Yabe, H., Nishikawa, N., et al. (2011). Zonisamide-induced long-lasting recovery of dopaminergic neurons from MPTP-toxicity. Brain Res. 1384, 170-178. doi: 10.1016/j.brainres. 2011.02.017

Choudhury, M. E., Sugimoto, K., Kubo, M., Iwaki, H., Tsujii, T., Kyaw, W. T., et al. (2012). Zonisamide up-regulated the mRNAs encoding astrocytic antioxidative and neurotrophic factors. Eur. J. Pharmacol. 689, 72-80. doi: 10.1016/ j.ejphar.2012.05.012

Claassen, D. O., Josephs, K. A., Ahlskog, J. E., Silber, M. H., Tippmann-Peikert, M., and Boeve, B. F. (2010). REM sleep behavior disorder preceding other aspects of synucleinopathies by up to half a century. Neurology $75,494-499$. doi: 10.1212/WNL.0b013e3181ec7fac

Condello, S., Curro, M., Ferlazzo, N., Costa, G., Visalli, G., Caccamo, D., et al. (2013). Protective effects of zonisamide against rotenone-induced neurotoxicity. Neurochem. Res. 38, 2631-2639. doi: 10.1007/s11064-013$1181-2$

Copeland, C. S., Neale, S. A., and Salt, T. E. (2013). Actions of Xanthurenic acid, a putative endogenous Group II metabotropic glutamate receptor agonist, on sensory transmission in the thalamus. Neuropharmacology 66, 133-142. doi: 10.1016/j.neuropharm.2012.03.009

Costa, C., Tozzi, A., Luchetti, E., Siliquini, S., Belcastro, V., Tantucci, M., et al. (2010). Electrophysiological actions of zonisamide on striatal neurons: selective neuroprotection against complex I mitochondrial dysfunction. Exp. Neurol. 221, 217-224. doi: 10.1016/j.expneurol.2009.11.002

de Lau, L. M. L., and Breteler, M. M. B. (2006). Epidemiology of Parkinson's disease. Lancet Neurol. 5, 525-535. doi: 10.1016/S1474-4422(06)70471-9

Evans, A. H., Pavese, N., Lawrence, A. D., Tai, Y. F., Appel, S., Doder, M., et al. (2006). Compulsive drug use linked to sensitized ventral striatal dopamine transmission. Ann. Neurol. 59, 852-858. doi: 10.1002/ana.20822

Fabbri, M., Ferreira, J. J., Lees, A., Stocchi, F., Poewe, W., Tolosa, E., et al. (2018). Opicapone for the treatment of Parkinson;'s disease: a review of a new licensed medicine. Mov. Disord. 33, 1528-1539. doi: 10.1002/mds.27475

Fazio, F., Lionetto, L., Molinaro, G., Bertrand, H. O., Acher, F., Ngomba, R. T., et al. (2012). Cinnabarinic acid, an endogenous metabolite of the kynurenine pathway, activates type 4 metabotropic glutamate receptors. Mol. Pharmacol. 81, 643-656. doi: $10.1124 / \mathrm{mol} .111 .074765$

Fox, S. H. (2013). Non-dopaminergic treatments for motor control in Parkinson's disease. Drugs 73, 1405-1415. doi: 10.1007/s40265-013-0105-4

Fox, S. H., Katzenschlager, R., Lim, S. Y., Barton, B., de Bie, R. M. A., Seppi, K., et al. (2018). International Parkinson and movement disorder society evidence-based medicine review: update on treatments for the motor symptoms of Parkinson's disease. Mov. Disord. 33, 1248-1266. doi: 10.1002/mds.27372

Freed, C. R., Greene, P. E., Breeze, R. E., Tsai, W. Y., DuMouchel, W., Kao, R., et al. (2001). Transplantation of embryonic dopamine neurons for severe Parkinson's disease. N. Engl. J. Med. 344, 710-719. doi: 10.1056/nejm200103083441002

Freitas, M. E., and Fox, S. H. (2016). Nondopaminergic treatments for Parkinson's disease: current and future prospects. Neurodegener. Dis. Manag. 6, 249-268. doi: 10.2217/nmt-2016-0005

Fukuyama, K., Tanahashi, S., Hoshikawa, M., Shinagawa, R., and Okada, M. (2014). Zonisamide regulates basal ganglia transmission via astroglial kynurenine pathway. Neuropharmacology 76(Pt A), 137-145. doi: 10.1016/j.neuropharm. 2013.08.002

Gluck, M. R., Santana, L. A., Granson, H., and Yahr, M. D. (2004). Novel dopamine releasing response of an anti-convulsant agent with possible anti-Parkinson's activity. J. Neural Transm. 111, 713-724. doi: 10.1007/s00702-004-0107-1

Greenamyre, J. T., and Hastings, T. G. (2004). Biomedicine. Parkinson's-divergent causes, convergent mechanisms. Science 304, 1120-1122. doi: 10.1126/science. 1098966
Grover, N. D., Limaye, R. P., Gokhale, D. V., and Patil, T. R. (2013). Zonisamide: a review of the clinical and experimental evidence for its use in Parkinson's disease. Indian J. Pharmacol. 45, 547-555. doi: 10.4103/0253-7613.121266

Hargus, G., Cooper, O., Deleidi, M., Levy, A., Lee, K., Marlow, E., et al. (2010). Differentiated Parkinson patient-derived induced pluripotent stem cells grow in the adult rodent brain and reduce motor asymmetry in Parkinsonian rats. Proc. Natl. Acad, Sci. U.S.A. 107, 15921-15926. doi: 10.1073/pnas.1010209107

Hossain, M. M., Weig, B., Reuhl, K., Gearing, M., Wu, L. J., and Richardson, J. R. (2018). The anti-parkinsonian drug zonisamide reduces neuroinflammation: role of microglial Nav 1.6. Exp. Neurol. 308, 111-119. doi: 10.1016/j.expneurol. 2018.07.005

Iijima, M., Osawa, M., Kobayashi, M., and Uchiyama, S. (2011). Efficacy of zonisamide in a case of Parkinson's disease with intractable resting and reemergent tremor. Eur. J. Neurol. 18, e43-e44. doi: 10.1111/j.1468-1331.2010. 03276.x

Ikeda, K., Hanashiro, S., Sawada, M., and Iwasaki, Y. (2015). Preliminary study of zonisamide monotherapy in de novo patients with early Parkinson's disease. Neurolo. Clin. Neurosci. 3, 163-166. doi: 10.1111/ncn3.179

Ikeda, K., Yanagihashi, M., Miura, K., Ishikawa, Y., Hirayama, T., Takazawa, T., et al. (2018). Zonisamide cotreatment delays striatal dopamine transporter reduction in Parkinson disease: a retrospective, observational cohort study. J. Neurol. Sci. 391, 5-9. doi: 10.1016/j.jns.2018.05.013

Ito, T., Yamaguchi, T., Miyazaki, H., Sekine, Y., Shimizu, M., Ishida, S., et al. (1982). Pharmacokinetic studies of AD-810, a new antiepileptic compound. Phase I trials. Arzneimittelforschung 32, 1581-1586.

Iwaki, H., Tagawa, M., Iwasaki, K., Kawakami, K., and Nomoto, M. (2019). Comparison of zonisamide with non-levodopa, anti-Parkinson's disease drugs in the incidence of Parkinson's disease-relevant symptoms. J. Neurol. Sci. 402, 145-152. doi: 10.1016/j.jns.2019.05.028

Janszky, J. (2009). [Role of zonisamid in treating epilepsy, Parkinson disorders and other neurological diseases]. Ideggyogy. Sz. 62, 383-389.

Kaplan, S., and Tarsy, D. (2013). Initial treatment of Parkinson's disease: an update. Curr. Treatm. Opt. Neurol. 15, 377-384. doi: 10.1007/s11940-013-0236-7

Kataoka, H., and Ueno, S. (2012). Nightmare-enacting behavior responding to zonisamide in early Parkinson's disease. Case Rep. Neurol. 4, 31-33. doi: 10. $1159 / 000336441$

Kawajiri, S., Machida, Y., Saiki, S., Sato, S., and Hattori, N. (2010). Zonisamide reduces cell death in SH-SY5Y cells via an anti-apoptotic effect and by upregulating MnSOD. Neurosci. Lett. 481, 88-91. doi: 10.1016/j.neulet.2010. 06.058

Kon, T., Ueno, T., Haga, R., and Tomiyama, M. (2018). The factors associated with impulse control behaviors in Parkinson's disease: a 2-year longitudinal retrospective cohort study. Brain Behav. 8:e01036. doi: 10.1002/brb3.1036

Kunisawa, N., Shimizu, S., Kato, M., Iha, H. A., Iwai, C., Hashimura, M., et al. (2018). Pharmacological characterization of nicotine-induced tremor: responses to anti-tremor and anti-epileptic agents. J. Pharmacol. Sci. 137, 162-169. doi: 10.1016/j.jphs.2018.05.007

Lew, M. (2007). Overview of Parkinson's disease. Pharmacotherapy 27(12 Pt 2), 155S-160S. doi: 10.1592/phco.27.12part2.155S

Liu, Y., Zhang, Y., Zhu, K., Chi, S., Wang, C., and Xie, A. (2020). Emerging role of sirtuin 2 in Parkinson's disease. Front. Aging Neurosci. 11:372. doi: 10.3389/ fnagi.2019.00372

Matsumoto, K., Miyazaki, H., Fujii, T., Kagemoto, A., Maeda, T., and Hashimoto, M. (1983). Absorption, distribution and excretion of 3(sulfamoyl[14C]methyl)-1,2-benziosoxazole (AD-810) in Rats, Dogs and Monkeys and of AD-810 in Men. Arzneimittelforschung 33, 961-968.

Matsunaga, S., Kishi, T., and Iwata, N. (2017). Combination therapy with zonisamide and antiparkinson drugs for parkinson's disease: a meta-analysis. J. Alzheimer's Dis. 56, 1229-1239. doi: 10.3233/jad-161068

Mendez, I., Sanchez-Pernaute, R., Cooper, O., Viñuela, A., Ferrari, D., Björklund, L., et al. (2005). Cell type analysis of functional fetal dopamine cell suspension transplants in the striatum and substantia nigra of patients with Parkinson's disease. Brain 128(Pt 7), 1498-1510. doi: 10.1093/brain/awh510

Miwa, H. (2007). Zonisamide for the treatment of Parkinson's disease. Expert Rev. Neurother. 7, 1077-1083. doi: 10.1586/14737175.7.9.1077

Mochio, S., Sengoku, R., Kono, Y., Morita, M., Mitsumura, H., Takagi, S., et al. (2012). Actigraphic study of tremor before and after treatment with zonisamide in patients with Parkinson's disease. Parkinsonism Relat. Disord. 18, 906-908. doi: 10.1016/j.parkreldis.2012.04.007 
Mollenhauer, B., Zimmermann, J., Sixel-Doring, F., Focke, N. K., Wicke, T., Ebentheuer, J., et al. (2016). Monitoring of 30 marker candidates in early Parkinson disease as progression markers. Neurology 87, 168-177. doi: 10.1212/ WNL.0000000000002651

Morita, S., Miwa, H., and Kondo, T. (2005). Effect of zonisamide on essential tremor: a pilot crossover study in comparison with arotinolol. Parkinsonism Relat. Disorde. 11, 101-103. doi: 10.1016/j.parkreldis.2004.09.004

Murata, M. (2004). Novel therapeutic effects of the anti-convulsant, zonisamide, on Parkinson's disease. Curr. Pharm. Des. 10, 687-693. doi: 10.2174/ 1381612043453180

Murata, M. (2009). [Pharmacologic treatment of Parkinson disease]. Brain Nerve $61,464-472$.

Murata, M., Hasegawa, K., and Kanazawa, I. (2007). Zonisamide improves motor function in Parkinson disease: a randomized, double-blind study. Neurology 68, 45-50. doi: 10.1212/01.wnl.0000250236.75053.16

Murata, M., Hasegawa, K., Kanazawa, I., Fukasaka, J., Kochi, K., and Shimazu, R. (2015). Zonisamide improves wearing-off in Parkinson's disease: a randomized, double-blind study. Mov. Disord. 30, 1343-1350. doi: 10.1002/mds.26286

Murata, M., Hasegawa, K., Kanazawa, I., Shirakura, K., Kochi, K., and Shimazu, R. (2016). Randomized placebo-controlled trial of zonisamide in patients with Parkinson's disease. Neurol. Clin. Neurosci. 4, 10-15. doi: 10.1111/ncn3. 12026

Murata, M., Horiuchi, E., and Kanazawa, I. (2001). Zonisamide has beneficial effects on Parkinson's disease patients. Neurosci. Res. 41, 397-399. doi: 10.1016/ s0168-0102(01)00298-x

Nakanishi, I., Kohmoto, J., Miwa, H., and Kondo, T. (2003). [Effect of zonisamide on resting tremor resistant to antiparkinsonian medication]. No Shinkei 55, 685-689.

Nakasa, H., Nakamura, H., Ono, S., Tsutsui, M., Kiuchi, M., Ohmori, S., et al. (1998). Prediction of drug-drug interactions of zonisamide metabolism in humans from in vitro data. Eur. J. Clin. Pharmacol. 54, 177-183. doi: 10.1007/ s002280050442

Nishijima, H., Miki, Y., Ueno, S., and Tomiyama, M. (2018). Zonisamide enhances motor effects of levodopa. Not of apomorphine, in a rat model of Parkinson's Disease. Parkinson's Dis. 2018:8626783. doi: 10.1155/2018/8626783

Ohmori, S., Nakasa, H., Asanome, K., Kurose, Y., Ishii, I., Hosokawa, M., et al. (1998). Differential catalytic properties in metabolism of endogenous and exogenous substrates among CYP3A enzymes expressed in COS-7 cells. Biochim. Biophys. Acta 1380, 297-304. doi: 10.1016/s0304-4165(97)00156-6

Ohtahara, S. (2006). Zonisamide in the management of epilepsy-Japanese experience. Epilepsy Res. 68(Suppl. 2), S25-S33. doi: 10.1016/j.eplepsyres.2005. 11.007

Okada, M., Kaneko, S., Hirano, T., Mizuno, K., Kondo, T., Otani, K., et al. (1995). Effects of zonisamide on dopaminergic system. Epilepsy Res. 22, 193-205. doi: 10.1016/0920-1211(95)00078-x

Oki, M., Kaneko, S., Morise, S., Takenouchi, N., Hashizume, T., Tsuge, A., et al. (2017). Zonisamide ameliorates levodopa-induced dyskinesia and reduces expression of striatal genes in Parkinson model rats. Neurosci. Res. 122, 45-50. doi: 10.1016/j.neures.2017.04.003

Olanow, C. W., Goetz, C. G., Kordower, J. H., Stoessl, A. J., Sossi, V., Brin, M. F., et al. (2003). A double-blind controlled trial of bilateral fetal nigral transplantation in Parkinson's disease. Ann. Neurol. 54, 403-414. doi: 10.1002/ ana. 10720

Omura, T., Asari, M., Yamamoto, J., Kamiyama, N., Oka, K., Hoshina, C., et al. (2012). HRD1 levels increased by zonisamide prevented cell death and caspase3 activation caused by endoplasmic reticulum stress in SH-SY5Y cells. J. Mol. Neurosci.46, 527-535. doi: 10.1007/s12031-011-9638-8

Omura, T., Kaneko, M., Okuma, Y., Matsubara, K., and Nomura, Y. (2013). Endoplasmic reticulum stress and Parkinson's disease: the role of HRD1 in averting apoptosis in neurodegenerative disease. Oxid. Med. Cell. Longev. 2013:239854. doi: 10.1155/2013/239854

Ondo, W. G. (2006). Essential tremor: treatment options. Curr. Treatm. Opt. Neurol. 8, 256-267. doi: 10.1007/s11940-006-0016-8

Ondo, W. G. (2007). Zonisamide for essential tremor. Clin. Neuropharmacol. 30, 345-349. doi: 10.1097/WNF.0b013e318074dd4f

Raja, M., and Bentivoglio, A. R. (2012). Impulsive and compulsive behaviors during dopamine replacement treatment in Parkinson's Disease and other disorders. Curr. Drug Saf. 7, 63-75. doi: 10.2174/157488612800492726
Rhee, Y.-H., Ko, J.-Y., Chang, M.-Y., Yi, S.-H., Kim, D., Kim, C.-H., et al. (2011). Protein-based human ips cells efficiently generate functional dopamine neurons and can treat a rat model of parkinson disease. J. Clin. Invest. 121, 2326-2335. doi: 10.1172/JCI45794

Rosler, T. W., Arias-Carrion, O., and Hoglinger, G. U. (2010). Zonisamide: aspects in neuroprotection. Exp. Neurol. 224, 336-339. doi: 10.1016/j.expneurol.2010. 04.017

Sano, H., Chiken, S., Hikida, T., Kobayashi, K., and Nambu, A. (2013). Signals through the striatopallidal indirect pathway stop movements by phasic excitation in the substantia nigra. J. Neurosci. 33, 7583-7594. doi: 10.1523/ JNEUROSCI.4932-12.2013

Sano, H., Murata, M., and Nambu, A. (2015). Zonisamide reduces nigrostriatal dopaminergic neurodegeneration in a mouse genetic model of Parkinson's disease. J. Neurochem. 134, 371-381. doi: 10.1111/jnc.13116

Sano, H., and Nambu, A. (2019). The effects of zonisamide on L-DOPA-induced dyskinesia in Parkinson's disease model mice. Neurochem. Int. 124, 171-180. doi: 10.1016/j.neuint.2019.01.011

Santos, C. M. (2012). New agents promote neuroprotection in Parkinson's disease models. CNS Neurol. Disord. Drug Targets 11, 410-418. doi: 10.2174/ 187152712800792820

Schapira, A. H. (2007). Treatment options in the modern management of Parkinson disease. Arch. Neurol. 64, 1083-1088. doi: 10.1001/archneur.64.8. 1083

Siebert, G. A., Pond, S. M., and Bryan-Lluka, L. J. (2000). Further characterisation of the interaction of haloperidol metabolites with neurotransmitter transporters in rat neuronal cultures and in transfected COS-7 cells. Naunyn Schmiedeberg's Arch. Pharmacol. 361, 255-264. doi: 10.1007/s002109900202

Sills, G., and Brodie, M. (2007). Pharmacokinetics and drug interactions with zonisamide. Epilepsia 48, 435-441. doi: 10.1111/j.1528-1167.2007.00983.x

Sonsalla, P. K., Wong, L. Y., Winnik, B., and Buckley, B. (2010). The antiepileptic drug zonisamide inhibits MAO-B and attenuates MPTP toxicity in mice: clinical relevance. Exp. Neurol. 221, 329-334. doi: 10.1016/j.expneurol.2009. 11.018

Stiff, D. D., Robicheau, J. T., and Zemaitis, M. A. (1992). Reductive metabolism of the anticonvulsant agent zonisamide, a 1,2-benzisoxazole derivative. Xenobiotica 22, 1-11. doi: 10.3109/00498259209053097

Tachibana, Y., Kita, H., Chiken, S., Takada, M., and Nambu, A. (2008). Motor cortical control of internal pallidal activity through glutamatergic and GABAergic inputs in awake monkeys. Eur. J. Neurosci. 27, 238-253. doi: 10. 1111/j.1460-9568.2007.05990.x

Tombini, M., Pellegrino, G., Di Pino, G., and Assenza, G. (2013). Zonisamide for seizures in Parkinson's disease with dementia. Seizure 22, 324-325. doi: 10.1016/j.seizure.2013.01.011

Tsujii, S., Ishisaka, M., and Hara, H. (2015a). Modulation of endoplasmic reticulum stress in Parkinson's disease. Eur. J. Pharmacol. 765, 154-156. doi: 10.1016/j. ejphar.2015.08.033

Tsujii, S., Ishisaka, M., Shimazawa, M., Hashizume, T., and Hara, H. (2015b). Zonisamide suppresses endoplasmic reticulum stress-induced neuronal cell damage in vitro and in vivo. Eur. J. Pharmacol. 746, 301-307. doi: 10.1016/j. ejphar.2014.09.023

Ueda, Y., Tokashiki, S., Kanemaru, A., and Kojima, T. (2012). Effect of zonisamide co-administration with levodopa on global gene expression in the striata of rats with Parkinson's disease. Biochem. Biophys. Res. Commun. 428, 401-404. doi: 10.1016/j.bbrc.2012.10.067

Uemura, M. T., Asano, T., Hikawa, R., Yamakado, H., and Takahashi, R. (2017). Zonisamide inhibits monoamine oxidase and enhances motor performance and social activity. Neurosci. Res. 124, 25-32. doi: 10.1016/j.neures.2017. 05.008

Ueno, S. I., Saiki, S., Fujimaki, M., Takeshige-Amano, H., Hatano, T., Oyama, G., et al. (2018). Zonisamide administration improves fatty acid beta-oxidation in Parkinson's Disease. Cells 8:14. doi: 10.3390/cells8010014

Uno, H., Kurokawa, M., Masuda, Y., and Nishimura, H. (1979). Studies on 3substituted 1,2-benzisoxazole derivatives. 6. Syntheses of 3-(sulfamoylmethyl)1,2-benzisoxazole derivatives and their anticonvulsant activities. J. Med. Chem. 22, 180-183. doi: 10.1021/jm00188a011

Voon, V., Sohr, M., Lang, A. E., Potenza, M. N., Siderowf, A. D., Whetteckey, J., et al. (2011). Impulse control disorders in Parkinson disease: a multicenter case-control study. Ann. Neurol. 69, 986-996. doi: 10.1002/ana.22356 
Wang, L., Kitai, S. T., and Xiang, Z. (2006). Activity-dependent bidirectional modification of inhibitory synaptic transmission in rat subthalamic neurons. J. Neurosci. 26, 7321-7327. doi: 10.1523/JNEUROSCI.4656-05. 2006

Wichmann, T., and DeLong, M. R. (2006). Basal ganglia discharge abnormalities in Parkinson's disease. J. Neural Transm. Suppl. 70, 21-25. doi: 10.1007/978-3211-45295-0_5

Willmore, L. J. (2005). Antiepileptic drugs and neuroprotection: current status and future roles. Epilepsy Behav. 7(Suppl. 3), S25-S28. doi: 10.1016/j.yebeh.2005. 08.006

Yagi, H., Ohkawara, B., Nakashima, H., Ito, K., Tsushima, M., Ishii, H., et al. (2015). Zonisamide enhances neurite elongation of primary motor neurons and facilitates peripheral nerve regeneration in vitro and in a mouse model. PLoS One 10:e0142786. doi: 10.1371/journal.pone.0142786

Yamamura, S., Ohoyama, K., Nagase, H., and Okada, M. (2009). Zonisamide enhances delta receptor-associated neurotransmitter release in striato-pallidal pathway. Neuropharmacology 57, 322-331. doi: 10.1016/j.neuropharm.2009. 05.005

Yang, L. P., and Perry, C. M. (2009). Zonisamide: in Parkinson's disease. CNS Drugs 23, 703-711. doi: 10.2165/00023210-200923080-00007

Yang, Y. C., Tai, C. H., Pan, M. K., and Kuo, C. C. (2014). The T-type calcium channel as a new therapeutic target for Parkinson's disease. Pflugers Arch. 466, 747-755. doi: 10.1007/s00424-014-1466-6

Yano, R., Yokoyama, H., Kuroiwa, H., Kato, H., and Araki, T. (2009). A novel anti-Parkinsonian agent, zonisamide, attenuates MPTP-induced neurotoxicity in mice. J. Mol. Neurosci. 39, 211-219. doi: 10.1007/s12031-0099181-z
Yokoyama, H., Yano, R., Kuroiwa, H., Tsukada, T., Uchida, H., Kato, H., et al. (2010). Therapeutic effect of a novel anti-parkinsonian agent zonisamide against MPTP (1-methyl-4-phenyl-1,2,3,6-tetrahydropyridine) neurotoxicity in mice. Metab. Brain Dis. 25, 135-143. doi: 10.1007/s11011-010-9191-0

Yoshikawa, T., Samata, B., Ogura, A., Miyamoto, S., and Takahashi, J. (2013). Systemic administration of valproic acid and zonisamide promotes differentiation of induced pluripotent stem cell-derived dopaminergic neurons. Front. Cell. Neurosci. 7:11. doi: 10.3389/fncel.2013.00011

Yurekli, V. A., Gurler, S., Naziroglu, M., Uguz, A. C., and Koyuncuoglu, H. R. (2013). Zonisamide attenuates MPP+-induced oxidative toxicity through modulation of $\mathrm{Ca} 2+$ signaling and caspase- 3 activity in neuronal PC12 cells. Cell. Mol. Neurobiol. 33, 205-212. doi: 10.1007/s10571-012-9886-3

Zesiewicz, T. A., Ward, C. L., Hauser, R. A., Sanchez-Ramos, J., Staffetti, J. F., and Sullivan, K. L. (2007). A double-blind placebo-controlled trial of zonisamide (zonegran) in the treatment of essential tremor. Mov. Disord. 22, 279-282. doi: $10.1002 / \mathrm{mds} .21282$

Conflict of Interest: The authors declare that the research was conducted in the absence of any commercial or financial relationships that could be construed as a potential conflict of interest.

Copyright (c) $2020 \mathrm{Li}$, Xue, Liu, Yang, Chi and Xie. This is an open-access article distributed under the terms of the Creative Commons Attribution License (CC BY). The use, distribution or reproduction in other forums is permitted, provided the original author(s) and the copyright owner(s) are credited and that the original publication in this journal is cited, in accordance with accepted academic practice. No use, distribution or reproduction is permitted which does not comply with these terms. 